\title{
Case Study on Hurricane Sandy Survivors Experience
}

DOI: 10.19085/journal.sijmas030301

\author{
DONNA TENNYSON \\ UNIVERSITY OF PHOENIX, PHOENIX AZ, USA. \\ IFY DIALA \\ UNIVERSITY OF PHOENIX, PHOENIX AZ, USA.
}

c) Scholedge International Journal of Multidisciplinary \& Allied Studies (2394-336X), Vol.03, Issue 03 (2016) pg67-75.

Published by: Scholedge R\&D Center [http://www.thescholedge.org/journals/] [Email: sijmas@scholedge.org]

\begin{abstract}
The goal of this qualitative single-case study was to investigate the problem with more than $50 \%$ of Americans admitting they are not prepared for natural disasters before they occur. The sample for this study was 24 purposively selected Hurricane Sandy survivors in New York and New Jersey who were 25 years of age or older. Data was collected through ten open-ended interview questions presented during telephone interviews. This study was guided by the theoretical framework of normative risk management decision making. Thematic analysis was used to code and analyze the data collected. This study was focused on answering two broad research questions related to why more than 50\% of Americans are not prepared for natural disasters before they occur and the factors that prevent them from preparing. The major recommendations for future research and practice were related to the lack of a distinction between individuals who perceive they are prepared (who are deemed unprepared according to regulatory guidelines) and the possibility they are included with the more than $50 \%$ of Americans who are not prepared although they require modification of preparedness behavior while individuals who are not prepared require adoption of preparedness behavior. The other recommendations describe the factors that prevent individuals from preparing as lack of notification and signaling communications that indicate a natural disaster is imminent and expected to be severe; and individual disbelief in the validity of the communications. This study contributes to filling the gap in the literature related to the lived experience with natural disasters.
\end{abstract}

Keywords: Hurricane Sandy, Disaster Preparedness, Climate change, Natural disaster

\section{Introduction}

On October 29, 2012 Hurricane Sandy (Sandy) struck the Northeast section of the United States. Sandy was the direct cause of 72 deaths and the indirect cause of an additional 87 deaths making it the deadliest storm in the United States since Hurricane Katrina (2005) and the deadliest storm to reach the eastern seaboard since Hurricane Agnes (1972) (Kiernan \&Lenhardt, 2013). Sandy caused an estimated $\$ 30$ billion in damage in the state of New Jersey and $\$ 40$ billion in damage in the state of New York making it the second most costly hurricane in the history of the United States after Hurricane Katrina's (2005) \$125 billion in damages (Hill, 2014).

Hurricane Sandy was a "tropical cyclone" that produced a severe storm surge along the coastline of the Northeast United States from New Jersey to Rhode Island. Sandy started as a tropical storm then underwent a transition, described by meteorologists as an "extratropical transition", before it reached New Jersey (Davis, Galarneau, \& Shapiro, 2013). “Extratropical 
transition" is a change that occurs when a "tropical cyclone" with a warm center elevates to an "extratropical cyclone" with a cold center that produces strong surface winds and extreme rainfall (Jones \&Thorncroft, 2000). Natural disasters, such as Hurricanes Katrina (2005) and Sandy (2012), serve as proof that disaster preparedness is important and that it must be enhanced at all levels starting with individuals. Disaster preparedness is the total of all measures taken and policies adopted to address a disaster before it occurs.

\section{Purpose and Significance of the Study}

The purpose of this qualitative single-case study was to investigate the problem with more than $50 \%$ of Americans not preparing for natural disasters before they occur. Twenty-four Hurricane Sandy survivors were interviewed to obtain information about preparedness actions or inactions, the impact those actions or inactions had on their experience with the natural disaster, and lessons others facing natural disasters can learn from their lived experience. The information about the lived experience and preparedness decisions, obtained from the Sandy survivors, may be generalizable to others facing natural disasters and provide valuable information that may change individual behavior regarding disaster preparedness activities. Natural disasters, such as hurricanes, tornados, and floods, have had a dramatic effect on human life and financial situations in recent years. Economic losses related to natural disasters have increased from $\$ 528$ billion (during 1981-1990) to $\$ 1.2$ trillion (from 20012010) (Kunreuther\& Michel-Kerjan, 2011). A gap currently exists in both the bereavement literature and the disaster literature about the difficulties of individual survivors, family systems, and communities that experienced disasters. The lessons learned that result from this study may contribute to the limited literature related to individual disaster preparedness and increase individual awareness regarding disaster preparedness. The results of this study may increase individual acceptance of activities related to preparing for disasters and the benefits that preparation activities provide.

\section{Discussions}

The following pages contain a review of the literature related to the experiences of several people who survived Hurricane Sandy and other natural disasters, climate change, natural disasters, and the decision making process that occurs with people who face disasters. This literature review focuses on obtaining information about the weather anomalies that resulted in Hurricane Sandy, the experiences of disaster survivors, and the decision making processes related to preparing for disasters.

\section{The Lived Experience}

The experiences of individuals and groups are the basis for concepts related to attaining native or local knowledge. Native and local knowledge concepts are rooted in cultural values and beliefs that serve as the basis for assessing risks and making choices (Abbott \& Wilson, 2014). Individual risk assessment involves making decisions that include either doing nothing, taking steps to mitigate the risk, or taking steps to adapt to the risk. Climate change is understood and interpreted by individuals according to their experiences which may conflict with scientific evidence that is available, but is nonetheless stored with their lived experiences.

Lived experiences are based on individual and collective ability to reflect, communicate with others to attain their knowledge or understanding, and the ability to respond with some type of action. Individual socio-economic situations, working opportunities, and capacities for taking action also effect individual perceptions of lived experiences. Knowledge about lived experiences is undoubtedly important for the social learning process that forms the basis for

http://dx.doi.org/10.19085/journal.sijmas030301 
individual durability, resilience, and sustainability with climate change (Johnson \& Wilson, 1999).

\section{Natural Disasters}

The threat of natural disasters may continue to increase due to the continuing rise in the average temperature of the waters in the oceans around the world (Kron, 2000). Global warming will cause extreme weather events to be more frequent and more intense, which will result in rising sea levels and other environmental changes (Berz, 1998). The natural disasters described in this topic are hurricanes (or tropical cyclones), floods, and tornados since they may be present the largest risk to human life and property due to their propensity for movement.

\section{Hurricanes (Tropical Cyclones)}

Studies indicate the strength of "tropical cyclones" (or hurricanes) is becoming more powerful with the most dramatic increase in the North Atlantic area of the United States (Elsner, 2008). The increase in the strength of hurricanes is associated with an increase in the temperature of the water in the ocean (Elsner, 2008). Academics, scientists, and researchers differ on the sources of the increase in the temperature of ocean water (Elsner, 2008). Several professionals attribute the increase to natural climate variations and others attribute it to "greenhouse gas" emissions created by humans (Elsner, 2008). Hurricanes are created through environmental interaction between a warm ocean (which provides nourishment for the storm), a calm atmosphere (which promotes the storm), and a subtropical high pressure cell (which provides forward direction) (Elsner, 2008). The increased temperature of the ocean causes the intensity of the storm to increase and increased winds could result in diffusing the heat into a hurricane (Elsner, 2008).

\section{Floods}

Flooding may result when rising water levels in rivers, streams, or the ocean overflow onto land due to severe rainfall that occurs over a short or long period of time; melting snow; structural failures; natural disasters, such as tropical cyclones; or some combination of the aforementioned factors (Ashley \& Ashley, 2008). Deaths attributed to, and the costs related to flood damage have steadily increased in the United States during the twentieth century (Downton, Miller, \&Pielke, 2005).

The majority of the flood related deaths studied (63\%) occurred in vehicles, which was directly correlated with the percent of deaths attributed to people walking through flood waters (Ashley \& Ashley, 2008). These factors were crucial for the conclusion that human behavior was a critical element of flood related fatalities; human behavior formed the basis for the recommendation that increases were needed in public awareness about safety measures for flood waters and education about the dangers of flood water.

\section{Tornados}

The strength of a tornado, the path a tornado may travel, and the size of an area affected by a tornado are forces of nature, that are dependent on the combination of factors that drive the development of a tornado, and they therefore cannot be controlled by humans. The only factors that may be affected by humans are the physical characteristics of homes and compliance with tornado warnings. Basements in houses are one means for finding shelter from tornados. 


\section{Disaster Preparedness}

Disaster preparedness is the total of all measures that have been taken and the policies that have been adopted to address a disaster before it occurs and to mitigate or minimize the effect the disaster has on human life (Introduction to preparedness, 2014). Disaster preparedness includes all the planning directed toward disasters, the resources used before a disaster occurs, and the resources used after a disaster has occurred; preparedness includes all activities directed toward saving lives and reducing the impact disasters have on individual and collective human life. Disaster preparedness includes measures a family, community, locale, country, region, institution, state, or federal government endorses to address the potential harmful effects of a disaster (Introduction to preparedness, 2014).

Disaster preparedness therefore receives flashes or short spans of attention after a severe weather event has occurred since obtaining resources for an area devastated by a hurricane because of ineffective preparation for and response to a disaster may be easier. Current disaster preparedness research indicates evidence of cultural and practical weaknesses related to preparedness behaviors, which are driven by conflicts between attitudes considered to be important across cultures at the same time considered to not be subjectively important within cultures. Demographic variables may also affect disaster preparedness decision making since people with small children and disabled individuals are more apt to embrace disaster preparedness. Education, income, and the level of vulnerability perceived by a disaster also effect the decisions related to preparing for a disaster (Adame et al., 2013).

\section{Disaster Risk Management}

The risk of a disaster is the probability or chance a natural or manmade event will occur and that it will have a harmful effect on human life, property, and/or the environment (Louw\& van Wyk, 2011). Natural events, such as earthquakes or hurricanes, may be caused by weather conditions that do not present a hazard alone; they become disasters due to the path they travel, such as over a region inhabited by people, and the strength they attain while travelling, such as elevating from a hurricane to a tropical storm. The larger the span of distance that a natural event travels after it reaches land, the greater the number of people; property; and environment it will affect (Egan, 2011).

Risk management encompasses activities, processes, or policies adopted or steps taken to reduce the impact an adverse event, such as a natural disaster, may have on people; property; and the environment. Disaster risk management is focused on reducing the impact of disasters on individuals, property, and communities through the adoption of a comprehensive process that includes preparing for a disaster before it occurs; enacting effective responses to disasters before, during, and after they occur; and recovering from disasters after they occur (Louw\& van Wyk, 2011). One area of disaster risk management is concerned with limiting the construction of homes in areas at high risk for disasters, as a means for managing the risks imminent disasters present. Scholars have recognized the role people play in the transformation of natural events into disasters (Pidot, 2013).

The disaster prevention field that focuses on the advantages of integrated disaster risk management (IDRM) is increasing. IDRM is designed to promote an overall increase in the quality of safety and security as an essential component of regions; cities; and communities at risk for disasters (Gopalakrishnan\& Okada, 2007). IDRM requires an assessment of disaster risk that includes consideration for human and economic losses at the community, regional, national, and global levels; the diversity and values of stakeholders; the reduction of regional vulnerability; and the development of proactive measures related to decreasing worldwide uncertainty (Gopalakrishnan\& Okada, 2007). The goal of IDRM is to develop innovative 
systems for responding to disasters in a way that mitigates the risks they pose or present (Gopalakrishnan\& Okada, 2007).

\section{Climate Change}

Several physical phenomena have been classified under the broad category of "climate change", which is often referred to as global warming although it includes much more than warming (Stern \& Weber, 2011). In 1959, an observatory in Hawaii noted the mean level of carbon dioxide $\left(\mathrm{CO}_{2}\right)$ in the atmosphere was 315 parts per million, which exceeded the maximum highest concentration of 300 parts per million revealed in a "420,000 year old icecore record" (Hecht \&Tirpak, 1995). Ice-core records are created when the surface of a glacier is compressed by the continual addition of snow to its surface; as ice crystals travel down the glacier (through the continual addition of snow), they grow and are closely packed into impenetrable masses that contain isolated bubbles (Bender et al., 1997).

The gases trapped in the bubbles are composed of the air that was in the atmosphere at the time the bubbles were created, in the ice, and scientific analysis allows scientists to learn about the atmospheric content of the air at the time the bubbles were created (Bender et al., 1997). By the end of the 1970's, the CO2 level in the ice-core records indicated it had increased to 335 parts per million (Hecht \&Tirpak, 1995). An investigation into the increases in the levels of $\mathrm{CO}_{2}$ requested by The Climate Research Board (1979) stated that if the levels continued to increase climate changes would occur and there was no reason to believe the changes would be minimal.

Scientists have clearly established collective knowledge about the climate changes that have occurred over the last 150 years (Stern \& Weber, 2011). The following assessments related to climate change are supported to a high level of confidence (National Research Council, 2010a):

- The average temperature of the surface of the earth is 1.4 degrees warmer during the 21st century than it was during the 20th century with the most intense warming occurring during the last thirty years (National Research Council, 2010a).

- Human burning of coal, oil, and natural gas for energy is the primary driver of the warming that has occurred over the last thirty years; climate variations that lead to year-over-year and decade-over-decade fluctuations are not the drivers of the longterm warming trend (National Research Council, 2010a).

- Global warming is the driver of a broad range of other climate changes, such as increases in the rate of severe rainfall; declining snow cover in the Northern Hemisphere and Arctic sea ice; increases in the warmth and frequency of "hot days and nights"; rising levels of the ocean; and widespread increases in the acidity of the ocean (National Research Council, 2010a).

- Climate changes pose individual and collective risks to a broad "range of human and environmental systems, including fresh water resources; the coastal environment; ecosystems; agriculture; fisheries; human health; and national security" (National Research Council, 2010a).

- Climate changes driven by humans and the impact of the changes to the climate will continue for many decades with the severity and impact of those changes dependent on the actions humans take to respond to those risks (National Research Council, 2010a).

http://dx.doi.org/10.19085/journal.sijmas030301 


\section{Methodology}

This qualitative, single-case study focused on the experiences of the survivors of Hurricane Sandy in New York and New Jersey, their level of preparedness for the disaster, and the impact their level of preparedness had on their perceptions of the phenomenon. Participants for this single-case study were purposively selected from individuals (over the age of 25) who were in New York or New Jersey on October 29, 2012 when Hurricane Sandy occurred. The participants for this study were Hurricane Sandy survivors who resided in the states of New York and New Jersey at the time the hurricane occurred. The method used to collect data was telephone interviews using open ended questions. Open ended questions were used to allow the researcher to gain a deeper understanding about the participant's experiences. This qualitative single-case study investigated the factors that prevent more than $50 \%$ of Americans from preparing for natural disasters and severe weather events before they occur. This research used the case study method since data was collected from multiple sources to explore the factors that prevented more than $50 \%$ of Americans from preparing for natural disasters (cases) before they occur. This single-case study was intrinsic in nature to gain an indepth understanding about Hurricane Sandy survivors' perceptions of their experience with the phenomenon. Intrinsic case studies are focused on providing an in-depth description of a specific individual, organization, or event. Secondary data was collected as a source for triangulation with the primary data collected. Secondary data was obtained from several sources including narratives written by or about the experiences of disaster survivors contained in minutes from meetings, multimedia presentations, journals, and abstracts contained in New York and New Jersey government websites. Government and relief organization websites containing information about natural disasters in the United States and lessons learned from survivors of those disasters (FEMA website and affiliate website, such as Ready.gov, and the American Red Cross) were also used as sources for secondary data. Well recognized newspapers in the New York and New Jersey areas were reviewed for narrative descriptions of experiences with natural disasters and policies enacted to reduce the impact of future natural disasters in those states.

The thematic analysis approach was used for analyzing the primary data (interview transcript data) collected during the telephone interviews and the secondary data regarding disaster survivors and preparedness. Thematic analysis is a systematic approach to qualitative data analysis that involves identifying themes or patterns of meaning; coding and classifying textual data according to themes; and interpreting the results by identifying commonalities, overarching patterns, or explanatory principles (Lapadat, 2010). Each category of primary data was interpreted and analyzed individually. Secondary data that triangulated with the categories of primary data (themes or word sequences that converge over three or more sources) were interpreted and analyzed separately. Primary data for each category of analysis and secondary data that triangulated the categories of primary data were saved in the Data Analysis file in Excel.

\section{Findings and Conclusions}

Five major themes emerged from data analysis: a) individuals may perceive they are prepared for natural disasters although their preparedness actions are not consistent with emergency services guidelines for preparedness, b) communications using multiple media are valuable for notifying the public about the approach of a storm, c) communications about the escalation of a storm may signal the strength of the storm and motivate individuals to prepare, d) living through natural disasters is an emotional experience from which others may learn, and e) natural disaster survivors may learn lessons from their experience that changes their future preparedness behavior and provides the opportunity for others to learn.

http://dx.doi.org/10.19085/journal.sijmas030301 


\section{Theme 1: Conclusion}

When the preparedness actions taken by the participants in this single-case study are compared to those outlined by FEMA and the Red Cross (as we did in the in-depth analysis) the shortcomings in the individual preparation actions and risk management decision making process become evident, causing the individuals to be considered not prepared for Hurricane Sandy before it occurred. The lack of preparation may be due to the inadequacies that can occur with the risk management decision making process or arbitrary selection of items for preparedness without assessing their relevance for addressing risks presented by the storm. Nonetheless it is possible that some of the $50 \%$ of Americans who were considered not prepared for natural disasters before they occurred, perceived they were prepared.

\section{Theme 2: Conclusion}

Multiple media and mass notifications were important elements of increasing the awareness about the approach of Sandy for the participants in this single-case study. Multiple media was used to notify large numbers of individuals located across New York and New Jersey about the approach of a potential natural disaster. Mass notifications were used to make accurate information available to the participants before the threat presented by Sandy occurred.

The lack of mass notifications may prevent individuals from preparing for natural disasters and severe weather conditions before they occur. The lack of mass notifications communicated before a forthcoming severe weather event escalates into a natural disaster may prevent individuals from being aware a natural disaster is imminent, having accurate information for the first two stages of the normative risk management decision making process, having time to determine and assess needed resources, and having time to prepare for the natural disaster before it occurs.

\section{Theme 3: Conclusion}

The lack of signaling communications or too much signaling may prevent some individuals from preparing for natural disasters before they occur. Signaling communications may trigger important steps in the disaster risk management decision making process by inciting individuals to research, analyze, and select alternatives that reduce the impact the disaster has on their lives and property. Individual inconsistencies with the decision making process regarding preparing for natural disasters may be another factor that prevents the majority of individuals from preparing for natural disasters before they occur.

\section{Theme 4: Conclusion}

Learning from others is a form of knowledge-in-use learning that is not only based on an individual's own activities, it takes the experience of others into consideration. The lack of knowledge about the emotional aspects of the experience with living through a natural disaster and the lived experience regarding natural disasters may be factors that prevent individuals from preparing for natural disasters before they occur.

\section{Theme 5: Conclusion}

A lack of information about lessons others learned to increase individual awareness about living through natural disasters may be a factor that prevents the majority of Americans from preparing for natural disasters before they occur. The lack of information about lessons learned by survivors of natural disasters may also deprive individuals facing natural disasters 
of valuable information, the opportunity to learn from the experiences of others, and prevent them from preparing for natural disasters before they occur.

\section{References}

Abbott, D., \& Wilson, G. (2014). Climate change: Lived experience, policy and public action. International Journal of Climate Change Strategies and Management, 6(1), 5-8.

Adame, B., Miller, C., \& Moore, S. (2013). Vested interest theory and disaster preparedness. Disasters, 37(1), 1-27. doi:10.1111/j.1467-7717.2012.01290.x

Ashley, S. T., \& Ashley, W. S. (2008). Flood fatalities in the United States. Journal of Applied Meteorology and Climatology, 47(3), 805-818.

Bender, M., Brook, E., \& Sowers, T. (1997). Gases in ice cores. Proceedings of the National Academy of Sciences, 94(16), 8343-8349

Berz, G. (1998, April). Catastrophes and climate change: Concerns and possible countermeasures of the insurance industry. Proceedings IPCC Adaption Workshop, Costa Rica, pp. 69-77

Davis, C. A., Galarneau, T. J., \& Shapiro, M. A. (2013). Intensification of Hurricane Sandy (2012) through extratropical warm core seclusion. Monthly Weather Review, 141(12), 42964321. doi:10.1175/MWR-D-13-00181.1

Downton, M. W., Miller, J. Z. B. \&Pielke Jr., R. A. (2005). Reanalysis of U.S. National Weather Service flood loss database. National Hazards Review, 6, 13-22.

Egan, M. (2011). Risk management. In K. Penuel, \& M. Statler (Eds.), Encyclopedia of disaster relief. (pp. 614-618). Thousand Oaks, CA: Sage Publications, Inc.

Elsner, J. B. (2008). Hurricanes and climate change. Bulletin of the American Meteorological Society, 89(5), 677-679. doi:10.1175/BAMS-89-5-677

Gopalakrishnan, C., \& Okada, N. (2007). Designing new institutions for implementing integrated disaster risk management: Key elements and future directions. Disasters, 31(4), 353-372. doi:10.1111/j.1467-7717.2007.01013.x

Hecht, A. D., \&Tirpak, D. (1995). Framework agreement on climate change: A scientific and policy history. Climatic Change, 29, 371-402.

Hill, D. (2014, January). Fighting back. Civil Engineering, 84(1), 50-55.

Introduction to preparedness. (2014). Scandinavian Journal of Public Health, 42(14), 148-150.

Johnson, H., \& Wilson, G. (1999). Institutional sustainability as learning. Development in Practice, 9(1), 43-55.

Jones, S. C., \&Thorncroft, C. D. (2000). The extratropical transitions of Hurricanes Felix and Iris in 1995, Weather Review, 128, 947-972

Kiernan, M. K., \&Lenhardt, M. F. (2013). What's in a name(d) storm? what sandy has taught us about flood, storm surge, and FEMA flood zones. FDCC Quarterly, 63(4), 318-339. 
Kron, W. (2000). Natural disasters: Lessons from the past - concerns for the future. Geneva Papers on Risk \& Insurance - Issues \& Practice, 25(4), 570-581.

Kunreuther, H., \& Michel-Kerjan, E. (2011). People get ready disaster preparedness. Issues in Science and Technology, 28(1), 39-50.

Lapadat, J. (2010). Thematic analysis. In A. Mills, G. Durepos, \& E. Wiebe (Eds.), Encyclopedia of case study research. (pp. 926-928). Thousand Oaks, CA: SAGE Publications, Inc.

Louw, E., \& van Wyk, S. (2011). Disaster risk management - planning for resilient and sustainable societies. Civil Engineering: Magazine of the South African Institution of Civil Engineering, 19(7), 16-18.

National Research Council. (2010a). Advancing the science of climate change. Washington, DC: National Academies Press.

Pidot, J. (2013). Deconstructing disaster. Brigham Young University Law Review, 2, 213-257.

Stern, P. C., \& Weber, E. U. (2011). Public understanding of climate change in the United States. American Psychologist, 66(4), 315-328. http://dx.doi.org/10.1037/a0023253 